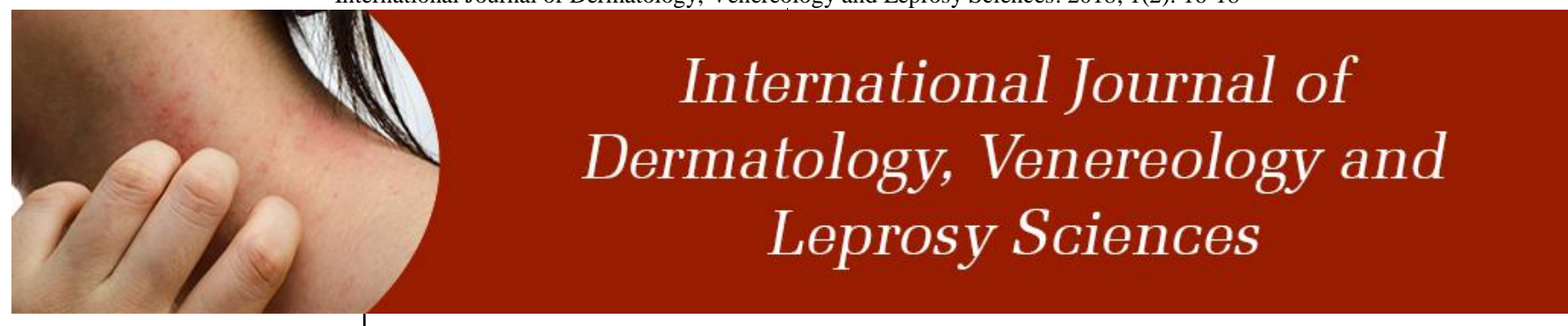

E-ISSN: 2664-942X

P-ISSN: 2664-9411

Derma 2018; 1(2): 16-18

Received: 13-05-2018

Accepted: 15-06-2018

Dr. Dev Mishra

Department of Dermatology,

Dr. Baba Saheb Ambedkar

Hospital,_Delhi, India

\section{Correspondence}

Dr. Dev Mishra

Department of Dermatology,

Dr. Baba Saheb Ambedkar

Hospital, Delhi, India

\title{
To determine cutaneous manifestation in diabetes patients- A clinical study
}

\section{Dr. Dev Mishra}

DOI: $\underline{\text { https://doi.org/10.33545/26649411.2018.v1.i2a.14 }}$

Abstract

Background: Diabetes mellitus affects individuals of all ages and in all socio-economic segments of the population. The present study was conducted to determine cutaneous manifestation in diabetes patients.

Materials \& Methods: The present study was conducted on 102 cases of diabetes patients of both genders reported to the department. Various types of skin lesions and duration of diabetes mellitus were recorded.

Results: Out of 102 patients, males were 60 and females were 42. Xerosis was seen in 27, diabetic dermopathy in 12, skin tags in 10, infection in 18, seborrheic keratosis in 4, Acanthosis nigricans in 6 , nail changes in 8 , diabetic rubeosis in 4 , lipodystrophy in 2 and diabetic bullae in 11 . The difference was significant $(P<0.05)$.

Conclusion: Common skin lesions in diabetes patients are xerosis, diabetic dermopathy, skin tags, seborrheic keratosis, Acanthosis nigricans, nail changes, diabetic rubeosis, lipodystrophy and diabetic bullae.

Keywords: Diabetes, Diabetic dermopathy, Seborrheic keratosis

\section{Introduction}

Diabetes mellitus affects individuals of all ages and in all socio-economic segments of the population. Global presence of type 2 diabetics in the year 2000 was 171 million which is likely to be 366 million in the year $2030^{[1]}$. The International Diabetes Federation (IDF) estimates the total number of diabetic subjects to be around 40.9 million in India and this is further set to raise to 69.9 million by the year 2025. Estimates by WHO suggest that the number of diabetic subjects would increase to 80 million by the year 2030 in India. Skin lesions are frequently observed in diabetic patients and about $30 \%$ of diabetics have cutaneous disorder ${ }^{[2]}$.

Diabetes is the most common endocrine disorder, affecting $8.3 \%$ of the population. Skin disorders will be present in $79.2 \%$ of people with diabetes ${ }^{[3]}$. Individuals with type 2 diabetes are more likely than those with type 1 diabetes to develop cutaneous manifestations. Cutaneous disease can appear as the first sign of diabetes or may develop at any time in the course of the disease. The cutaneous signs of diabetes are the manifestations of multiple factors. Abnormal carbohydrate metabolism, other altered metabolic pathways, atherosclerosis, microangiopathy, neuronal degeneration and impaired host mechanism all play a role ${ }^{[4]}$. Although some cutaneous reactions are secondary to treatment, simple skin manifestation may be the first clue to an underlying deadly disease not less than diabetes. This has stimulated interest to all diabetic care providers, inclusive of dermatologists for development of an early detection system for markers of DM, of which skin is a vital organ and which demands due honor in the work up list in connection with diabetes mellitus [5]. The present study was conducted to determine cutaneous manifestation in diabetes patients.

\section{Materials \& Methods}

The present study was conducted in the department of Dermatology. It comprised of 102 cases of diabetes patients of both genders reported to the department. The study was approved from the institutional ethical committee. All were informed regarding the study and written consent was obtained. 
Data such as name, age, gender etc. was recorded. Detailed clinical history followed by general physical examination, systemic examination and mucocutaneous examination was done in all. Various types of skin lesions and duration of diabetes mellitus were recorded. Results were subjected to statistical analysis. $\mathrm{P}$ value less than 0.05 was considered significant.

\section{Results}

Table I: Distribution of patients

\begin{tabular}{|c|c|c|}
\hline \multicolumn{3}{|c|}{ Total- 102 } \\
\hline Gender & Males & Females \\
\hline Number & 60 & 42 \\
\hline
\end{tabular}

Table I shows that out of 102 patients, males were 60 and females were 42 .

Table II: Type of cutaneous lesions

\begin{tabular}{|c|c|c|}
\hline Lesions & Number & \multirow{2}{*}{ P value } \\
\hline Xerosis & 27 & \\
\hline Diabetic dermopathy & 12 & \multirow{2}{*}{0.01} \\
\hline Skin tags & 10 \\
\hline Infection & 18 & \\
\hline Seborrheic keratosis & 4 & \\
\hline Acanthosis nigricans & 6 & \\
\hline Nail changes & 8 & \\
\hline Diabetic rubeosis & 4 & \\
\hline Lipodystrophy & 2 & \\
\hline Diabetic bullae & 11 \\
\hline
\end{tabular}

Table II, graph I shows that xerosis was seen in 27, diabetic dermopathy in 12, skin tags in 10, infection in 18 , seborrheic keratosis in 4, Acanthosis nigricans in 6, nail changes in 8 , diabetic rubeosis in 4 , lipodystrophy in 2 and diabetic bullae in 11 . The difference was significant $(\mathrm{P}<$ $0.05)$.

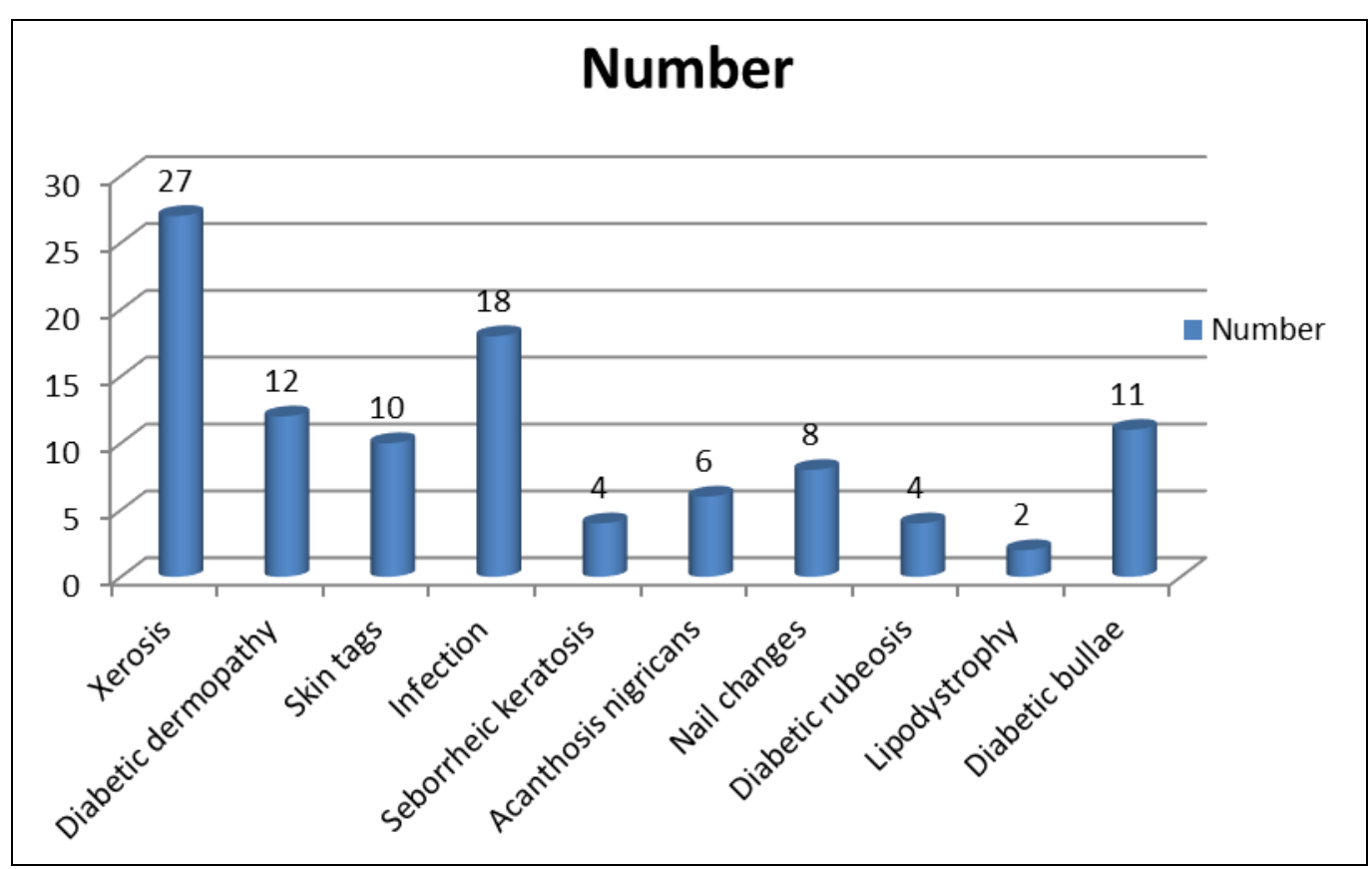

Graph I: Type of cutaneous lesions

\section{Discussion}

Cutaneous signs of diabetes mellitus are extremely valuable to the clinician. They generally appear after the primary disease has developed but may signal or appear coincidentally with its onset, or even precede diabetes by many years ${ }^{[6]}$. Diabetes mellitus (DM) wreaks havoc all over the body, and the skin is not exempted from the attack. Insulin affects the utilization of glucose in skin and is required for growth and differentiation of keratinocytes and fibroblasts. The condition of skin has long provided clues to the presence of diabetes. This includes frequent infections, dryness, nonspecific pruritus etc. In the last few years many new associations between diabetes mellitus and the skin have been noted and we have a better understanding now of the pathophysiology of some diabetic complications ${ }^{[7]}$.
Microcirculatory alteration, glycosylation of different proteins with production of advanced glycosylated end product and their subsequent deposition in the basement membrane and alterations in the lipid profile results in changes of the skin condition of diabetic patients. Diabetes also alters endothelial functions ${ }^{[8]}$. The present study was conducted to determine cutaneous manifestation in diabetes patients.

In this study, out of 102 patients, males were 60 and females were 42 . A study of 750 patients with diabetes found that the most common skin manifestations were cutaneous infections $(47.5 \%)$, xerosis $(26.4 \%)$, and inflammatory skin diseases $(20.7 \%)^{[9]}$.

We found that xerosis was seen in 27 , diabetic dermopathy in 12 , skin tags in 10 , infection in 18 , seborrheic keratosis in 
4, Acanthosis nigricans in 6, nail changes in 8 , diabetic rubeosis in 4, lipodystrophy in 2 and diabetic bullae in 11 . Thappa ${ }^{[10]}$ found that sixty consecutive subjects with diabetes mellitus having dermatological manifestations were selected. Bacterial infections were the commonest dermatological disorder $(46.7 \%)$. Different forms of dermatophyte infections and candidiasis were found in $30 \%$ and $23.3 \%$ subjects, respectively. Diabetic dermopathy or 'shin spot' and diabetic foot with gangrenous changes were found in $20 \%$ and $13.3 \%$ subjects, respectively. Skin manifestations associated with diabetes were the second most common skin disorders and constituted $43.3 \%$. Pruritus of unknown origin and xerosis (13.3\%) were the most common cutaneous abnormalities in the group associated with diabetes. Other cutaneous manifestations, namely pigmented purpuric dermatosis $(6.6 \%)$, psoriasis $(3.3 \%)$, vitiligo $(6.6 \%)$, lichen planus $(3.3 \%)$, porokeartosis $(3.3 \%)$, sclerosis, diabetic thick skin and contracture $(6.6 \%)$, lipodystrophy $(3.3 \%)$, skin rashes $(6.6 \%)$ and scar with abscess $(1.6 \%)$, were very rare.

Baidya et al. [11] evaluated the prevalence of skin manifestations in patients with diabetes mellitus. One hundred consecutive patients with the diagnosis of diabetes mellitus and having skin lesions, either attending the diabetic clinic or admitted in medical wards were included in this study. The common skin disorders were: Xerosis (44\%), diabetic dermopathy (36\%), skin tags (32\%), cutaneous infections $(31 \%)$, and seborrheic keratosis $(30 \%)$. Bossen $^{12}$ found that cutaneous infections were seen in $31 \%$ of patients. Fungal infections were seen in $16 \%$ of the patients (9\% had candidal and $7 \%$ had dermatophytosis). Bacterial infections were seen in $15 \%$ of the patients. It is widely believed that diabetic patients have an increased risk for infectious diseases.

\section{Conclusion}

Common skin lesions in diabetes patients are xerosis, diabetic dermopathy, skin tags, seborrheic keratosis, Acanthosis nigricans, nail changes, diabetic rubeosis, lipodystrophy and diabetic bullae.

\section{References}

1. Bhat YJ, Gupta V, Kudyar RP. Cutaneous manifestations of diabetes mellitus. Int $\mathrm{J}$ Diab Dev Ctries. 2006; 26:152-5.

2. Sasmaz S, Buyukbese MA, Cetinkaya A, Celik M, Arican O. The prevalence of skin disorders in type-2 diabetic patients. Int J Dermatol 2005; 3:1.

3. Ragunatha S, Anitha B, Inamadar AC, Palit A, Devarmani SS. Cutaneous disorders in 500 diabetic patients attending diabetic clinic. Indian $\mathrm{J}$ Dermatol 2011; 56:160-164

4. McCash S, Emanuel PO. Defining diabetic dermopathy. J Dermatol. 2011; 38:988-992

5. Paron NG, Lambert PW. Cutaneous manifestations of diabetes mellitus. Prim Care. 2000; 27:371-383

6. Martínez DP, Díaz JÓF, Bobes CM. Eruptive xanthomas and acute pancreatitis in a patient with hypertriglyceridemia. Int Arch Med 2008; 1:6.

7. Romano C, Massai L, Asta F, Signorini AM. Prevalence of dermatophytic skin and nail infections in diabetic patients. Mycoses 2001; 44: 83.

8. Gupta AK, Konnikov N, Macdonala P, Rich P, Rodger NW et al. Prevalence and epidemiology of toenail onychomycosis in diabetic subject: A multicentic survey. Br J Dermatol. 1998; 139:665.

9. Huntley AC. The cutaneous manifestations of diabetes mellitus. J Am Acad Dermatol. 1982; 7:427-455.

10. Thappa DM. Skin tags as markers of diabetes mellitus: An epidemiological study in India. J Dermatol. 1995; 22:729-31.

11. Baidya A, Halder AK, Datta PK. Spectrum of Cutaneous Manifestations of Diabetes Mellitus: An Observational Study from a Tertiary Care Hospital. J Diabetes Metab 2018; 9:791.

12. Bossen B. The epidemiology of foot lesions in diabetic patients aged 15-50 years. Diabet Med. 1990; 7:438. 